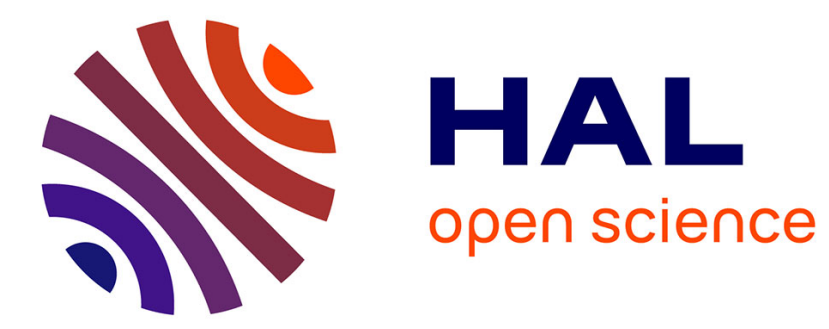

\title{
A pinch of RNA spices up DNA repair \\ Mauro Modesti
}

\section{To cite this version:}

Mauro Modesti. A pinch of RNA spices up DNA repair. Materials Science-Poland, 2018. hal02144122

\section{HAL Id: hal-02144122 \\ https://hal.science/hal-02144122}

Submitted on 29 May 2019

HAL is a multi-disciplinary open access archive for the deposit and dissemination of scientific research documents, whether they are published or not. The documents may come from teaching and research institutions in France or abroad, or from public or private research centers.
L'archive ouverte pluridisciplinaire HAL, est destinée au dépôt et à la diffusion de documents scientifiques de niveau recherche, publiés ou non, émanant des établissements d'enseignement et de recherche français ou étrangers, des laboratoires publics ou privés. 
The rapid wound-induced spread of a calcium signal is visualized using a genetically encoded reporter. Scale bar, $1 \mathrm{~mm}$.

membrane-localized GLR3.4 protein, is the only plant GLR for which ion channel activity and gating by glutamate has been demonstrated (6). Clade 3 GLRs also are the only GLRs to contain a motif found in metabotropic glutamate receptors (mGluRs) (4). mGluRs function in a diversity of processes, including responses to pain and noxious stimuli $(7,8)$, which are related to wounding responses. Whether these particular features of the GLR3s in plants tie them to their function in wounding or other processes awaits further investigation.

An important question raised by this study is, how does this long-distance calcium signal move through the plant? In the mammalian nervous system, glutamate is a local signal that induces a long-distance ionic response. Glutamate is released into the nerve synapse from synaptic vesicles, where it binds to iGRs on the postsynaptic neuron, opening these ion channels and allowing influx of calcium ions and other cations. The ion influx induces membrane potential changes that lead to signal propagation (3). The results of Toyota et al. suggest an endocrine action of glutamate, which is dissimilar from glutamate as a neurotransmitter in mammals and more akin to a hormonal role of glutamate. This mode of action is supported by the observations that the fluorescent calcium ion reporter GCaMP3 localizes to the vasculature and that GLR3.6 is found in the cells that line the vasculature, where other woundsignaling molecules, such as jasmonates, are synthesized (9). A fluorescent glutamate sensor was also used to show that glutamate was increased at the site of wounding; this signal extends along the vasculature and exits the leaf after wounding, which is consistent with a mobile glutamate signal. These results suggest a model in which herbivore and mechanical wounding releases glutamate into the vascular system, where it can travel long distances and activate GLR3 ion channels in the plasma membrane of cells that line the vasculature. This increases the calcium ion influx into these cells. Consistent with this model, GLR3.3 and GLR3.6 were previously shown to be required for systemic wound-activated surface potential changes that are linked to the predicted behavior of these proteins as gated ion channels (10-12). GLR3 activity is required for the increased synthesis of enzymes of the jasmonate biosynthesis pathway in leaves distant from the wound site $(1,10)$, leading to the accumulation of jasmonates, which convey host resistance to various invading organisms (9). Additional experiments are needed to determine whether the rate of long-distance glutamate movement is sufficient to drive the rapid long-distance calcium changes.

The findings of Toyota et al. are only possible because of the powerful advances in microscopy and biosensors that were used for these observations. The authors used two calcium ion sensors and a glutamate sensor visualized by means of imaging approaches that allow detection of the dynamics of rapidly transmitted longdistance signals. The availability of a microscope that can capture a large field of view with a highly efficient camera that is sensitive enough to detect relatively weak fluorescence, and that is capable of time-lapse imaging to capture rapid signal transduction, provides insight that was not previously possible.

This combination of approaches has the potential to provide additional evidence for the importance of glutamate and GLRs in plant signaling (2). Future experiments are needed to resolve whether glutamate is moving long distances rather than acting via the localized release and long-distance propagation of ionic signals. In addition to measuring long-distance glutamate biosensor changes, another approach is to use labeled glutamate to show that this amino acid is released at wounds and travels through the vasculature to distant undamaged leaves to initiate defense responses. The possibility that glutamate may participate in systemic signaling to modulate developmental and environmental responses across the plant kingdom is an exciting avenue for future studies.

\section{REFERENCES}

1. M. Toyota et al., Science 361, 1112 (2018),

2. B.G. Forde, J. Exp. Bot. 65,779 (2014)

3. S. F. Traynelis et al.,Pharmacol. Rev. 62,405 (2010).

4. M. M. Wudicketal., J. Exp. Bot. 10.1093/jxb/ery153 (2018).

5. M. B. Price, J. Jelesko, S. Okumoto, Front. Plant Sci. 3,235 (2012).

6. E. D. Vincill, A. M. Bieck, E. P. Spalding, Plant Physiol. 159 , 40 (2012)

7. S. Chiechio, F. Nicoletti, Curr. Opin. Pharmacol. 12,28 (2012).

8. G. R. Elliott, S. P. Leys, J. Exp. Biol. 213,2310 (2010).

9. M. L. Campos, J.H. Kang, G. A. Howe, J. Chem. Ecol. 40,657 (2014).

10. S. A. Mousavi, A. Chauvin, F. Pascaud, S. Kellenberger, E.E. Farmer, Nature 500, 422 (2013).

11. V. Salvador-Recatalà, W. F. Tjallingii, E. E. Farmer, New Phytol. 203,674 (2014).

12. V. Salvador-Recatala, Plant Signal. Behav. 11 , el161879 (2016).

10.1126/science.aau9813

\section{GENETICS}

A pinch of
RNA spices up
DNA repair

Transient incorporation of RNA precursors helps fix broken DNA

\section{By Mauro Modesti}

W

hen DNA is replicated by DNA polymerases, deoxyribonucleotides are incorporated, whereas when DNA is transcribed by RNA polymerases, ribonucleotides are used. The misincorporation of ribonucleotides into DNA occurs frequently during DNA replication (1). However, the presence of ribonucleotides in DNA makes it more fragile and threatens genome stability that needs to be maintained for faithful transmission of genetic information. To counteract this, cells have evolved efficient ribonucleotide removal strategies that rely on ribonuclease H2 (RNase H2) (2). On page 1126 of this issue, Pryor et al. (3) report the surprising discovery that ribonucleotides are frequently incorporated at broken DNA ends, which enhances repair. This important finding overturns the central dogma of molecular biology by demonstrating that transient incorporation of ribonucleotides in DNA has a biological function.

DNA double-strand breaks (DSBs) in the genome arise through the action of external agents such as exposure to ionizing radiation or clastogenic chemicals. They are also caused endogenously by reactive oxygen species produced during oxidative metabolism or when DNA replication forks collapse. In addition, DSBs initiate programmed genome rearrangements including $\mathrm{V}(\mathrm{D}) \mathrm{J}$ recombination in developing lymphocytes that shuffles antigen and $\mathrm{T}$ cell receptor gene segments during the adaptive immune response; or during the process of meiotic recombination in germ cells. DSBs are repaired either by homologous recombination or by nonhomologous end joining (NHEJ) path-

Cancer Research Center of Marseille, CNRS UMR7258; Inserm UMR1068, Aix Marseille Université U105: Institut Paoli Calmettes, 27 Boulevard Lei Roure CS30059, 13273 Marseille, Cedex 09, France.Email: mauro.modesti@inserm.fr 
ways. In mammals, the canonical NHEJ (c-NHEJ) pathway primarily repairs DSBs induced by exposure to ionizing radiation or by the endonuclease encoded by the recombinationactivating genes 1 and 2 that initiates $\mathrm{V}(\mathrm{D}) \mathrm{J}$ recombination (4). Individuals with deficiencies in c-NHEJ suffer from radiosensitive severe combined immunodeficiency disorders and genome instability that leads to deleterious chromosomal aberrations.

DSBs induced by exposure to ionizing radiation and $\mathrm{V}(\mathrm{D}) \mathrm{J}$ recombination have complex DNA end structures that require processing by nucleases and DNA polymerases to generate suitable substrates for the c-NHEJ pathway component DNA ligase 4 (LIG4), which joins DNA ends by phosphodiester bond catalysis. Among the DNA processing enzymes involved in c-NHEJ, X-family polymerases, including the ubiquitous DNA polymerase $\mu(\mathrm{Pol} \mu)$ and lymphocyte-specific terminal deoxynucleotidyl transferase (TdT), are key for the ability of c-NHEJ to adapt to complex end structures at broken termini $(5,6)$. However, Pol $\mu$ and TdT are special DNA polymerases because they are poor at discriminating the sugar moiety (ribose or deoxyribose) of the nucleotide used during DNA synthesis at broken DNA ends. In vitro, both enzymes can incorporate ribonucleotides almost as efficiently as deoxyribonucleotides into DNA $(7,8)$. Therefore, Pryor et al. examined whether ribonucleotides are incorporated during cNHEJ in mouse fibroblasts and pre-B cells, and if so, how this affects NHEJ.

The authors found that ribonucleotides are frequently incorporated during c-NHEJ, during $\mathrm{V}(\mathrm{D}) \mathrm{J}$ recombination and DSB repair of simple blunt-ended DSBs induced by CRISPR-Cas9 (which is used for genome editing) but that are extended by TdT. Within 1 minute, up to $60 \%$ of DSB junctions contained ribonucleotides, but ribonucleotides were absent at repaired DSBs 30 minutes later. Ribonucleotide incorporation was dependent on Pol $\mu$ (one ribonucleotide incorporated per junction) and TdT (average of 2.7 nucleotides incorporated per junction, likely all ribonucleotides), and their removal dependent on RNase H2.

What is the advantage of incorporating ribonucleotides during DSB repair by c-NHEJ? Pryor et al. find that the presence of a terminal ribonucleotide favors direct ligation of complex mispaired DNA end structures, which are typically formed by exposure to ionizing radiation and $\mathrm{V}(\mathrm{D}) \mathrm{J}$
Model of the ribo-NHEJ mechanism

Pryor et al. propose that DSBs with complex ends are repaired by a rapid and coordinated triple strand repair mechanism.

DSB with mispaired complex ends

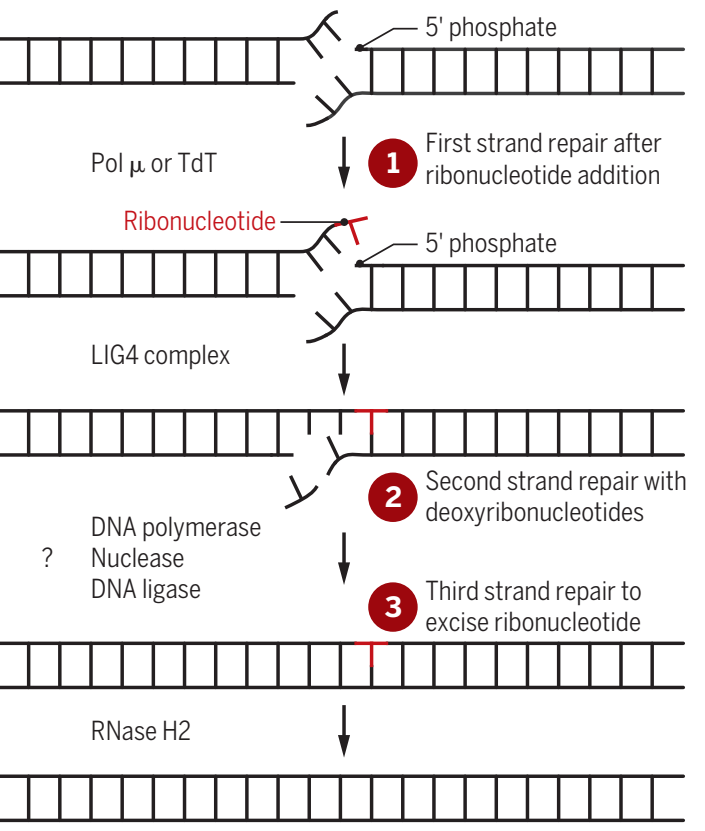

ribose) polymerase 1 (PARP1), LIG3, and $\mathrm{XRCC1}$ (x-ray repair cross-complementing protein 1) interact with c-NHEJ components $(10,11)$. These factors could be involved in the second strand repair step of ribo-NHEJ. Advanced super-resolution microscopy has enabled direct visualization of NHEJ components at DSBs in cells (12) and should now be used to identify and probe the recruitment of the ribo-NHEJ components. It will also be important to determine how ribo-NHEJ components functionally interact with other DNA repair factors. Pryor et al. show that when high levels of deoxyribonucleotides are artificially introduced in cells, c-NHEJ is impaired and thus nucleotide pool imbalances, often detected in cancer cells and regulated during cell cycle progression, could influence DSB repair pathway choice.

Moreover, further detailed analysis of the ribo-NHEJ machinery should help design strategies for genome editing with CRISPR-Cas9. Pryor et $a l$. paved the way toward that goal by showing that coexpression of TdT

recombination. Moreover, a terminal ribonucleotide uniquely stimulates ligation by LIG4. Thus, ribonucleotide addition may help channel repair to the c-NHEJ pathway as opposed to other DSB repair pathways, such as alternative NHEJ (a-NHEJ) or homologous recombination that rely on complementarity base pairing to connect the broken ends. Additionally, c-NHEJ is faster than the other DSB repair pathways (9) and given that ribonucleotides are more abundant than deoxyribonucleotides inside cells, incorporation of ribonucleotides might allow rapid repair kinetics so that interference with DNA replication or transcription is minimized and rejoining unrelated DSB ends is avoided.

What is the mechanism of this riboNHEJ pathway? The authors propose a triple strand repair model (see the figure), involving sequential strand repair whereby, after a ribonucleotide is added by Pol $\mu$ or TdT to the $3^{\prime}$ end of the DSB end, strand continuity is restored by LIG4; this is followed by repair, by undetermined enzymes, of the other strand through addition of deoxyribonucleotides; and finally, the ribonucleotides are excised in an RNase H2-dependent process. The entire pathway is so rapid that the authors suggest that this triple strand repair process is tightly coordinated and may involve interaction between components of different DNA repair pathways. Interestingly, the a-NHEJ DNA repair proteins poly(ADP- and Cas9 changes the sequence spectra of NHEJ junctions by increasing the frequencies of two nucleotide insertions, which could facilitate gene deletion studies.

Beneficial roles for ribonucleotide incorporation in DNA have been identified previously (13). For example, ribonucleotide incorporation in DNA was implicated in mating-type switching in yeast, and for helping strand discrimination during DNA mismatch repair in eukaryotic cells. It is likely that further studies will unveil other physiological roles for ribonucleotide incorporation in DNA.

\section{REFERENCES AND NOTES}

1. J. S. Williams et al., Nat. Rev. Mol. Cell Biol. 17,350 (2016).

2. M.A.M. Reijns etal.,Cell 149,1008(2012)

3. J. M. Pryor et al., Science 361, 1126 (2018)

4. M. R. Lieber, Annu. Rev. Biochem. 79, 181 (2010).

J. Loc'h, M. Delarue, Curr. Opin. Struct. Biol. 53, 22 (2018).

6. M. J. Martin, L. Blanco, Nucleic Acids Res. 42, 7923 (2014).

7. A. F. Moonet al., Nucleic Acids Res. 45, 9138 (2017).

8. J. B. Boulé et al., J. Biol. Chem. 276, 31388 (2001).

9. J.A. Kochan et al., Nucleic Acids Res. 45, 12625 (2017)

10. M.Xing etal., Nat. Commun. 6, 6233 (2015).

11. A. Craxtonetal., Cell Death Differ. 22, 890 (2015).

12. D. A. Reid et al.,Proc. Natl. Acad. Sci. U.S.A. 112, E2575 (2015)

13. C. J. Potenski, H. L. Klein, Nucleic Acids Res. 42, 10226 (2014).

\section{ACKNOWLEDGMENTS}

M.M. thanks K. Meek for critical reading of the manuscript and the French National Research Agency, the French National Cancer Institute, and the French National League Against Cancer for support 


\section{Science}

\section{A pinch of RNA spices up DNA repair}

Mauro Modesti

Science 361 (6407), 1069-1070.

DOI: $10.1126 /$ science.aau9194

ARTICLE TOOLS

RELATED

CONTENT

REFERENCES

PERMISSIONS http://science.sciencemag.org/content/361/6407/1069

http://science.sciencemag.org/content/sci/361/6407/1126.full

This article cites 13 articles, 3 of which you can access for free http://science.sciencemag.org/content/361/6407/1069\#BIBL

http://www.sciencemag.org/help/reprints-and-permissions

Science (print ISSN 0036-8075; online ISSN 1095-9203) is published by the American Association for the Advancement of Science, 1200 New York Avenue NW, Washington, DC 20005. 2017 @ The Authors, some rights reserved; exclusive licensee American Association for the Advancement of Science. No claim to original U.S. Government Works. The title Science is a registered trademark of AAAS. 